9. Han Qiaoyun, Zhang Yi, Li Kongqing, Zou Shenghua. Computational evaluation of cooling system under deep hot and humid coal mine in China: A thermal comfort study // Tunnelling and Underground Space Technology. - 2019. - V. 90. - P. 394-403.

10. Левин, Л.Ю., Зайцев А.В., Бутаков С.В., Семин М.А. Нормализация микроклиматических условий горных выработок при отработке глубокозалегающих запасов калийных рудников // Горн. журн. 2018. - № 8. - С. 97-102.

УДК 622.4

DOI:10.7242/echo.2020.1.17

\title{
МОДЕЛИРОВАНИЕ ПРОЦЕССА ИЗМЕНЕНИЯ СОСТАВА РУДНИЧНОГО ВОЗДУХА В НАКЛОННОЙ ТУПИКОВОЙ ГОРНОЙ ВЫРАБОТКЕ
}

\author{
Е.В. Колесов, Б.П. Казаков \\ Горный институт УрО РАН, г. Пермь
}

\begin{abstract}
Аннотация: приведены результаты численного трехмерного моделирования аэродинамических процессов в наклонной тупиковой горной выработке, проветриваемой за счет общешахтной депрессии. Осуществляется выбор и обоснование алгоритма численного трехмерного моделирования динамики двухфазной смеси «воздух-сернистый газ» с использованием CFD-методов. На базе построенной модели производится оценка глубины проветривания тупиковой выработки за счет турбулентной диффузии, а также возможность стратификации газовоздушной смеси по высоте выработки и дальнейшего «стекания» тяжелой газовой фракции $\mathrm{SO}_{2}$ (сернистого газа).

Ключевые слова: вентиляция горных выработок, трехмерное численное моделирование, турбулентность, стратификация газовоздушной смеси.
\end{abstract}

\section{Введение}

Согласно существующим правилам безопасности действующие выработки должны проветриваться активной струей воздуха за счет общешахтной депрессии, либо с помощью вентиляторов местного проветривания, если речь идет о тупиковых выработках [1-2]. Недействующие вертикальные и наклонные выработки должны иметь надежное перекрытие, а доступ людей в непроветриваемые выработки должен быть закрыт. В не проветриваемых активной струей воздуха тупиковых выработках возможно не только превышение концентрации ядовитых газов выше ПДК, но и уменьшение содержания кислорода в воздухе [3-5]. Экспериментальные измерения в недействующей наклонной тупиковой выработке рудника Таймырский ПАО «ГМК «Норильский никель» выявили уменьшение содержания кислорода с 20,9\% вблизи устья до 2,6 \% вблизи забоя (при этом кислород был пропорционально замещен азотом и другими газами, входящими в состав воздуха). Одной из гипотез уменьшения содержания кислорода в тупиковой выработке была следующая последовательность событий. В ходе химической реакции окисления сульфидной руды кислород в воздухе тупиковой выработки заместился более тяжелым, чем воздух, сернистым газом $\mathrm{SO}_{2}$ (плотность 2,77 кг/м ${ }^{3}$ ). После этого сернистый газ отслоился ближе к почве тупиковой выработки, под действием силы тяжести опустился к устью, и далее был вынесен воздушной струей, идущей по сквозной выработке. Для проверки или опровержения этой гипотезы был применен аппарат вычислительной аэродинамики.

\section{Содержательная постановка задачи}

Исследуемая область представляет собой тупиковую непроветриваемую выработку с поворотом и часть сквозной проветриваемой выработки в области их сопряжения. Тупиковая выработка имеет вертикальный подъем под углом $16^{\circ}$ длиной около 70 метров. В ходе обследования тупиковой выработки специалистами были выполнены отборы 
проб воздуха. Содержание кислорода на участке от тупика (завала горной породы) до поворота составило в среднем 2,6 \%. У поворота содержание кислорода составляло 8,9 \% и увеличивалось до 20,1 \% в пяти метрах от сопряжения со сквозной выработкой. Содержание кислорода в сквозной выработке составило 20,9\%.

В рамках моделирования аэрогазодинамических процессов, происходящих в тупиковой выработке, поставлены две задачи:

1. Определение расстояния (глубины проветривания), отсчитываемого от устья тупиковой выработки, на котором действует турбулентная диффузия, вызванная движением воздушной струи, идущей по сквозной выработке.

2. Оценка расслоения (стратификации) газовоздушной среды («легкий» воздух + «тяжелый» сернистый газ) и возможность «стекания» тяжелой фракции к устью выработки.

В модуле SpaceClaim программного комплекса ANSYS построена упрощенная трехмерная модель тупиковой выработки и часть сквозной выработки в области их сопряжения (см. рис. 1).

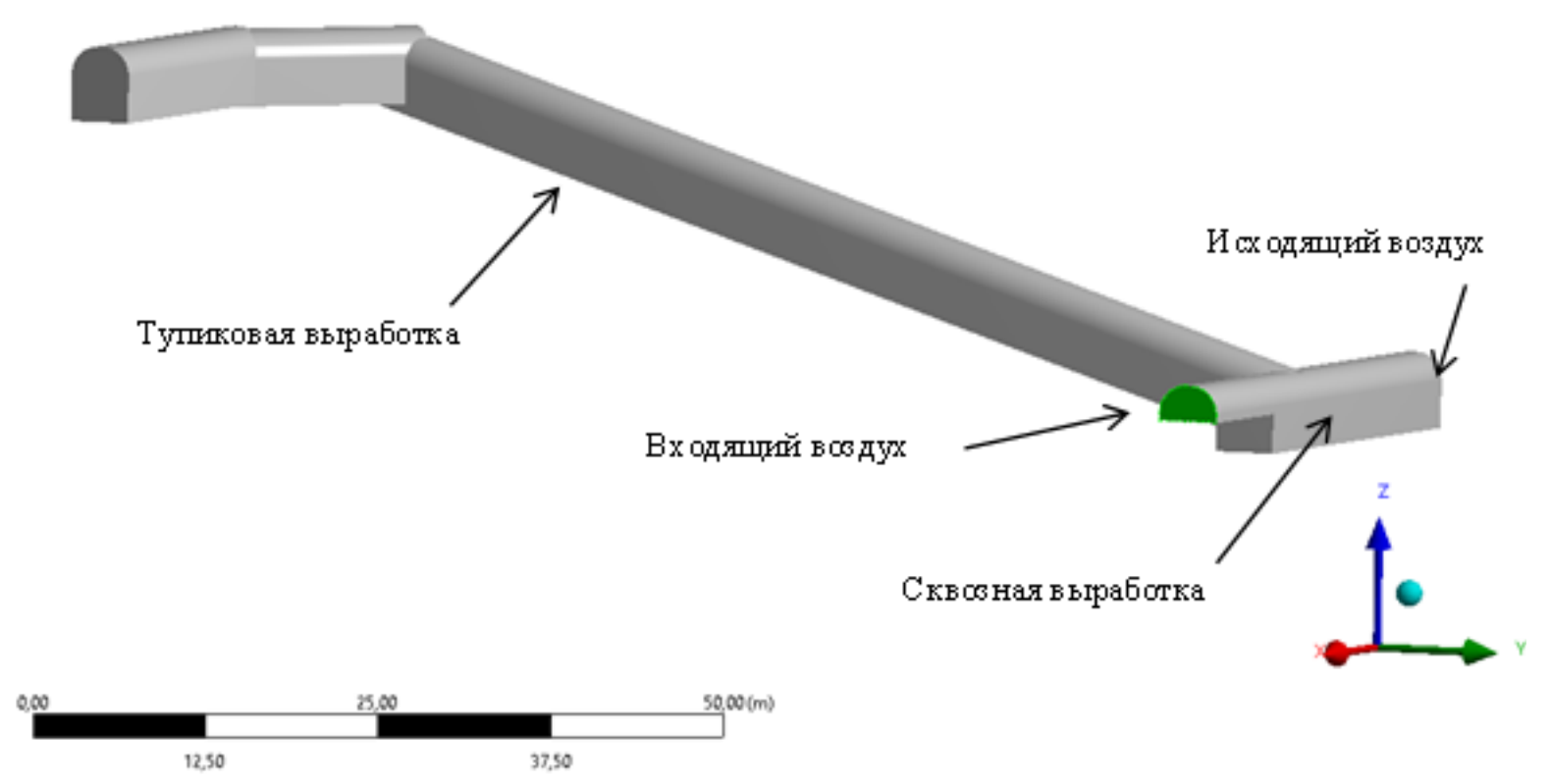

Рис. 1. Геометрическая модель расчетной области

\section{Физическая модель движения газовоздушной смеси. \\ Моделирование течения воздуха}

В литературе представлено множество работ, связанных с применением методов вычислительной аэродинамики для решения задач рудничной вентиляции [6-10].

Для определения поля скоростей воздуха используются усредненные по Рейнольдсу уравнения Навье-Стокса. Для определения кинетической энергии турбулентности использовалась двухпараметрическая модель турбулентности standard k-epsilon [11-13].

Воздушный поток поступает в расчетную область по сквозной выработке (рис. 1). Средняя скорость воздуха во входном сечении расчетной области $5 \mathrm{~m} / \mathrm{c}$, интенсивность турбулентности $I_{t u r b}=2 \%$, масштаб вихрей турбулентности $l_{\text {turb }}=0.2 \mathrm{M}$.

Воздушный поток, проходя по сквозной выработке и частично проникая в тупиковую выработку, покидает расчетную область через поверхность, показанную на рис. 1. На данной поверхности задается нулевое статическое давление, интенсивность турбулентности $I_{t u r b}=2 \%$, масштаб вихрей турбулентности $l_{t u r b}=0.2$ м.

На стенках горных выработок задается «прилипание» потока. Расчет пограничного слоя осуществляется с учетом повышенной шероховатости стенок горных выработок. 


\section{Метод численного расчета}

Исследуемая расчетная область разбивается на конечные элементы, а решаемая система математических уравнений записывается в конечно-объемной форме. Неизвестными параметрами задачи в данном случае становятся значения скоростей воздуха в узлах конечных объемов и значения давлений воздуха.

На рис. 2 представлена нерегулярная тетраэдрическая конечно-объемная сетка с призматическим пограничным слоем на границах с твердыми стенками.

В процессе исследования построено несколько конечно-объемных сеток разного качества для анализа независимости получаемого решения от способа дискретизации расчетной области. Анализ независимости решений от способа дискретизации расчетной области производился на основе сравнения перепадов полного давления, получаемых в результате расчета воздухораспределения в тупиковой выработке для разных сеток при фиксированной заданной скорости воздуха на входе в расчетную область.

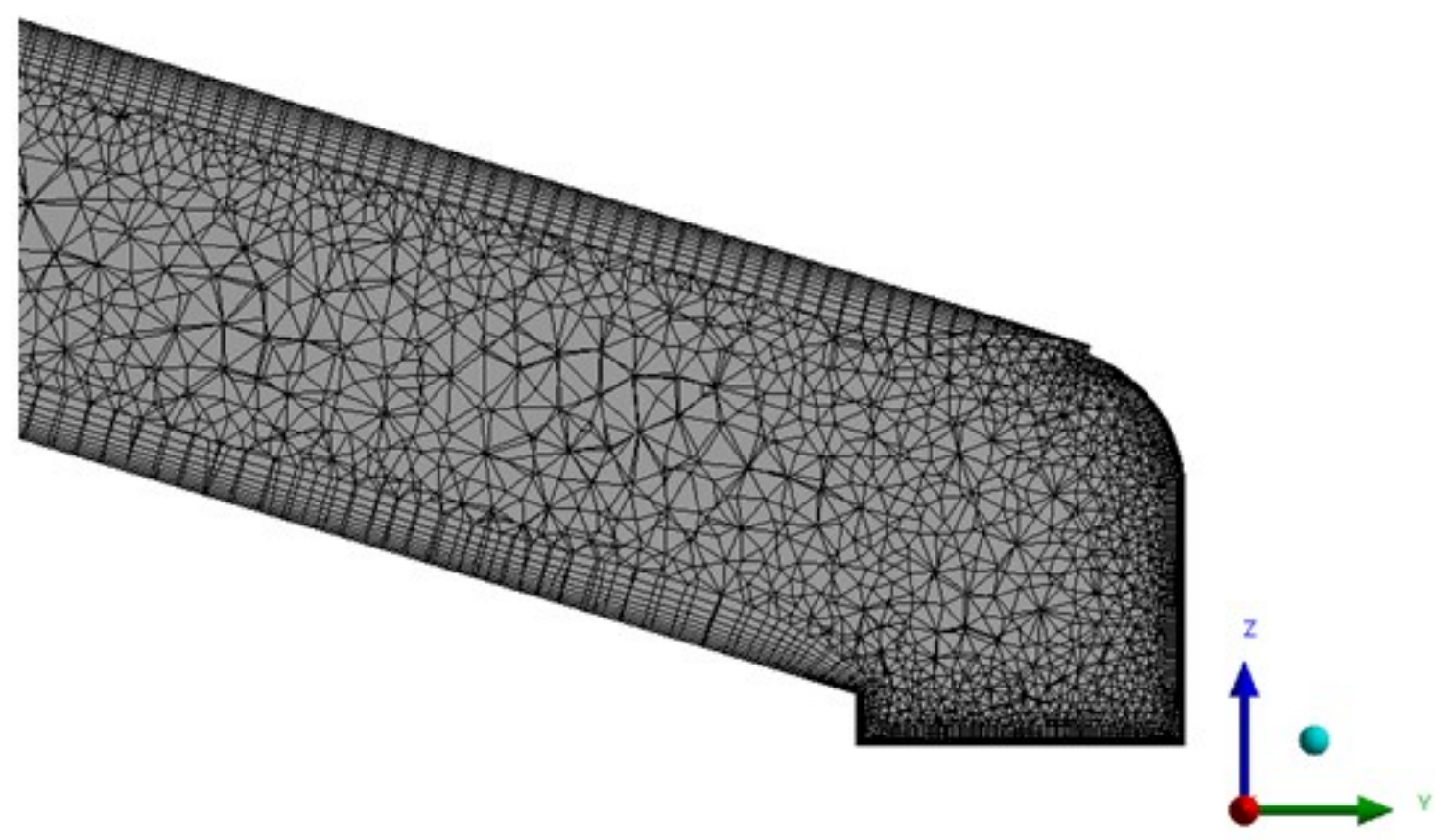

Рис. 2. Срединный продольный разрез расчетной области (тупиковой выработки), разбитой на конечные элементы

В результате анализа выбрана конечно-объемная сетка со следующими общими свойствами: количество узлов - 1189 528; количество объемов (элементов) - 2915350.

Для определения распределения скоростей и давлений пылевоздушной смеси использовался алгоритм численного расчета Semi-Implicit Pressure Linked Equations $[10,13]$ — частично неявный метод для уравнений со связью по давлению. Использовался первый порядок точности пространственной дискретизации по уравнениям (3), (4) и второй порядок точности пространственной дискретизации по уравнениям (1), (6).

Для ускорения расчета проводилось распараллеливание вычислений между 8-ю ядрами центрального процессора с использованием платформы MPI Local Parallel.

\section{Моделирование воздухораспределения}

На предварительном этапе проводился расчет распределения скорости и давления воздуха в тупиковой выработке. Это необходимо для проверки независимости решений от способа дискретизации расчетной области, а также для анализа структуры потоков воздуха в окрестности сопряжения сквозной и тупиковой выработок. 
На рис. 3 представлено распределение скорости воздуха в продольном вертикальном сечении тупиковой выработки в момент установления стационарного воздухораспределения. Показано, что воздух из сквозной выработки проникает в тупиковую выработку за счет турбулентной диффузии примерно на треть ее длины (около 25 м). В оставшейся части тупиковой выработки движение воздуха отсутствует.

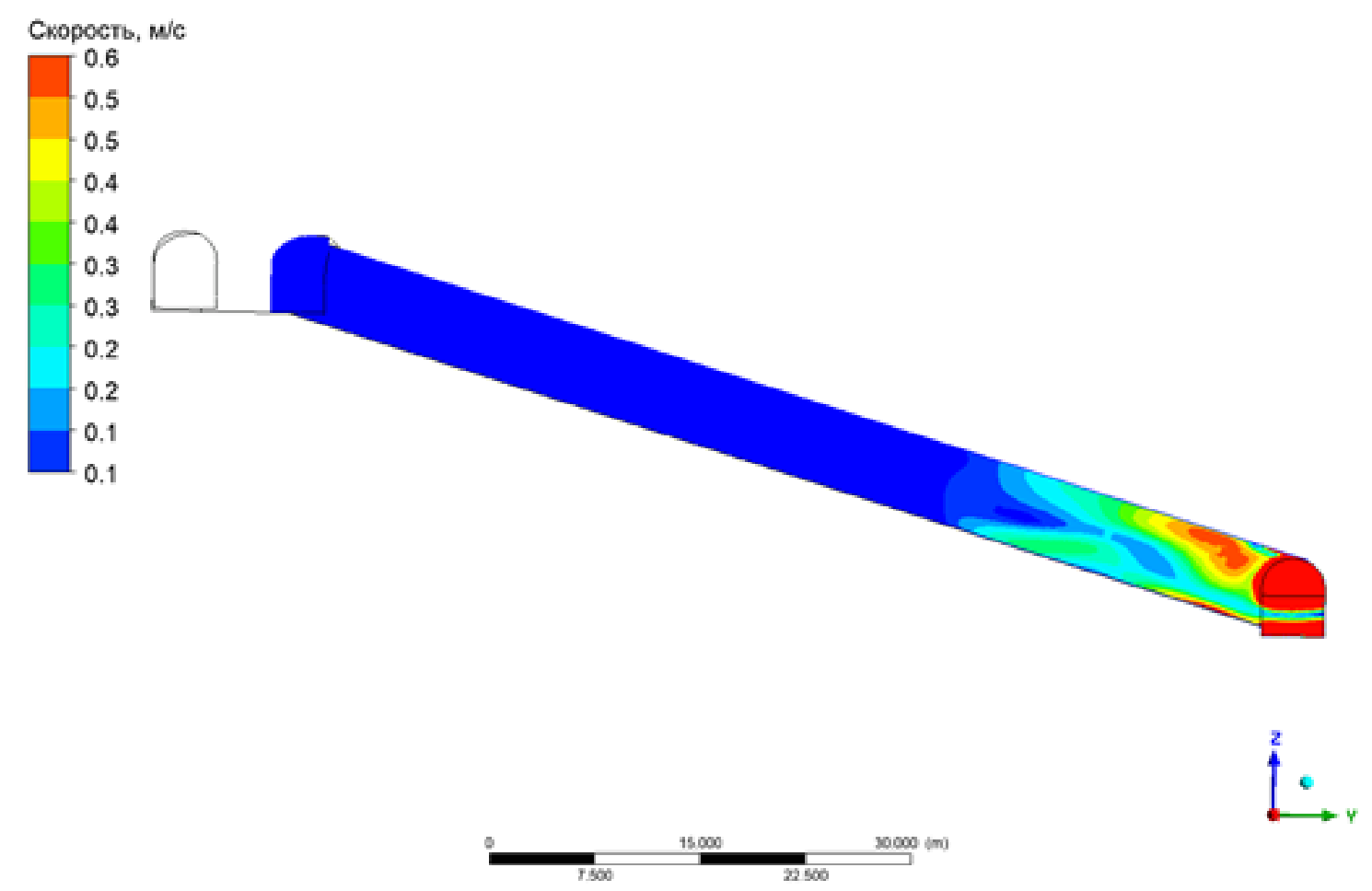

Рис. 3. Распределение скоростей в срединном продольном вертикальном сечении тупиковой выработки

\section{Моделирование динамики сернистого газа}

Моделирование динамики сернистого газа в газовоздушном пространстве тупикового забоя осуществлялось в рамках модели двухфазной Эйлеровой среды. В данном случае воздух является первой, несущей фазой, а сернистый газ - второй, дисперсной фазой. В рамках рассматриваемого подхода Эйлера к описанию двухфазной смеси газовое облако, как и воздух, представляется в виде сплошного континуума, характеризующегося плотностью смеси $\rho_{d}$, истинной плотностью $\rho_{d}^{i}$, объемной долей $r_{d}$, концентрацией $c_{d}$ и вектором скорости $\vec{V}_{d}[14]$.

Истинная плотность сернистого газа принималась равной 2,77 кг/м ${ }^{3}$. Плотность смеси - это масса сернистого газа $m_{d}$, находящаяся в единице объема воздушного пространства $\Delta V$ :

$$
\rho_{d}=\frac{m_{d}}{\Delta V}=\frac{\rho_{d}^{i} \Delta V_{d}}{\Delta V}=\rho_{d}^{i} \cdot r_{d}
$$

Таким образом, объемная доля $r_{d}$ характеризует объем $\Delta V_{d}$, занимаемый сернистым газом в единичном объеме воздушного пространства $\Delta V$.

При построении физической модели динамики сернистого газа использовалось допущение, что начальная объемная доля сернистого газа в газовоздушной смеси составляет $17 \%$, т. е. моделируется ситуация, когда в ходе химической реакции окисления сульфидной руды почти весь кислород в воздухе тупиковой выработки заместился сернистым газом:

$$
2 \mathrm{FeS}_{2}+5 \mathrm{O}_{2} \rightarrow 2 \mathrm{FeO}+4 \mathrm{SO}_{2}
$$


Для определения динамики сернистого газа решается уравнение неразрывности дисперсной фазы

и уравнение переноса концентрации $c_{d}$ :

$$
\frac{\partial \rho_{d}}{\partial t}+\nabla \cdot\left(\rho_{d} V\right)=0
$$

$$
\frac{\partial \rho_{d} c_{d}}{\partial t}+\nabla \cdot\left(\rho_{d} c_{d} V-\rho_{d} \cdot D_{d} \nabla c_{d}\right)=0
$$

Здесь в качестве скорости $V$ принимается скорость воздуха, $D_{d}$ - диффузионность сернистого газа, $\mathrm{m}^{2} / \mathrm{c}$.

Уравнения переноса кинетической турбулентной энергии и диссипации турбулентной энергии остаются прежними. Результатом решения является стационарное (не зависимое от времени) распределение плотности газовоздушной смеси по высоте (см. рис. 4). При этом наблюдается несущественное отклонение от среднего значения плот-

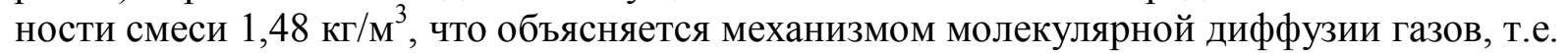
проникновения молекул одного вещества (воздуха) между молекулами другого (сернистого газа), приводящий к самопроизвольному выравниванию их концентраций по всему занимаемому объёму.

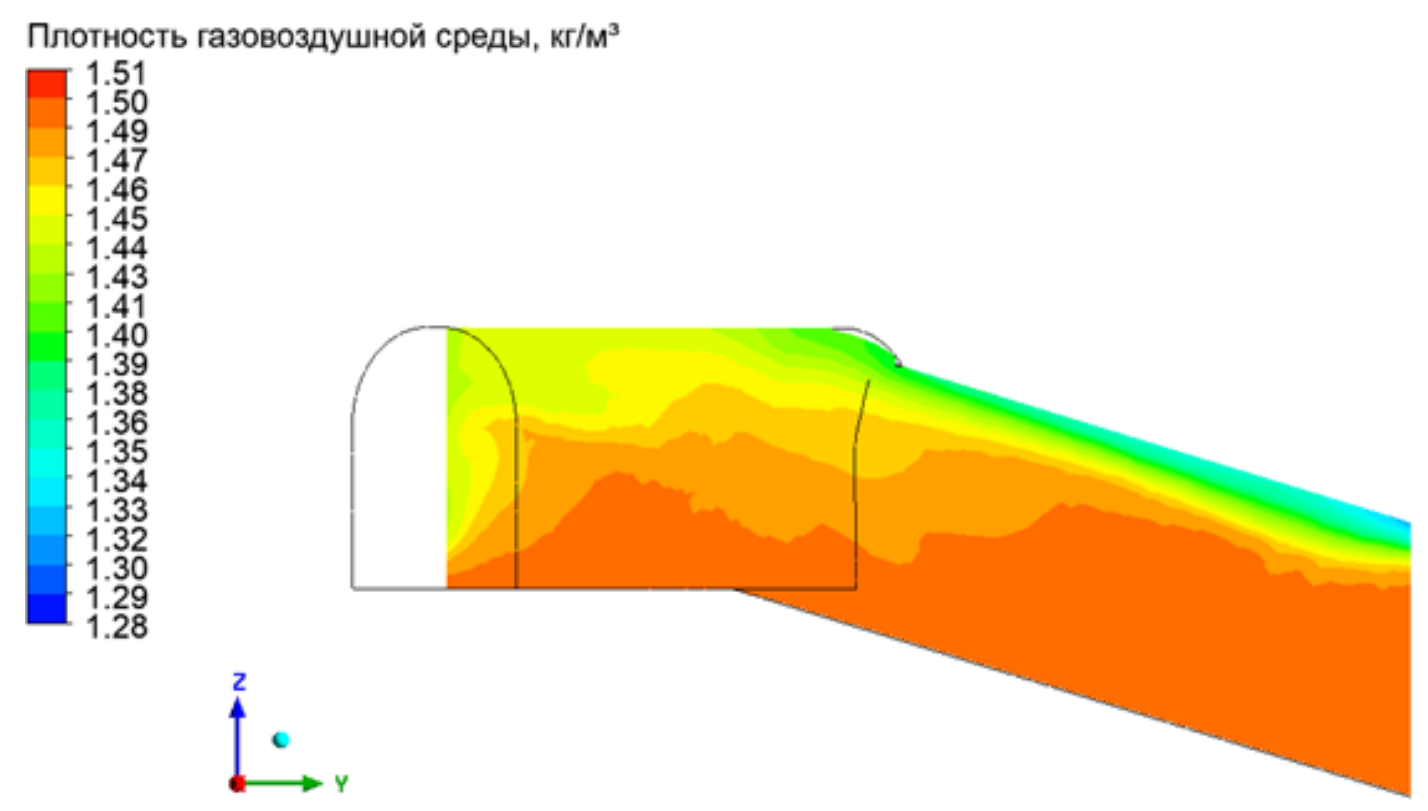

Рис. 4. Распределение плотности газовоздушной среды по срединному вертикальному сечению тупиковой выработки

\section{Выводы}

По итогам проведенного исследования получены следующие основные результаты:

1. на основе трехмерного численного моделирования газодинамических процессов определена глубина проветривания наклонной тупиковой выработки за счет турбулентной диффузии: 25 метров от устья. В остальной части выработки движение воздуха отсутствует;

2. результаты численного моделирования показали, что в случае замещения кислорода сернистым газом в тупиковой непроветриваемой части выработки за счет механизма молекулярной диффузии происходит перемешивание газов (воздуха и сернистого газа), и расслоения газов и дальнейшего «стекания» тяжелой фракции (сернистого газа) не наблюдается.

Исследование выполнено при поддержке Уральского отделения РАН в рамках научного проекта № 18-5-5-5 и Российского фонда фундаментальных исследований в рамках научного проекта № 19-35-90076 


\title{
БИБЛИОГРАФИЧЕСКИЙ СПИСОК
}

1. Колесов Е.В. Обоснование последовательного проветривания рабочих зон нескольких тупиковых выработок // Стратегия и процессы освоения георесурсов: сб. науч. тр. Вып. 16 / ГИ УрО РАН. Пермь, 2018. - С. 291-295. DOI: 10.7242/gdsp.2018.16.78

2. Колесов Е.В. Разработка методики расчета количества воздуха, требуемого для проветривания тупиковых проходческих выработок после взрывных работ // Горное эхо. - 2019. - № 3 (76). - С. 80-84. DOI: 10.7242/echo.2019.3.22.

3. Ушаков К.З. Газовая динамика шахт. - М.: Изд-во МГГУ, 2004. - 480 с.: ил.

4. Колесов Е.В., Шалимов А.В., Семин М.А. Разработка мероприятий по отводу взрывоопасных газов из выработанного пространства при затоплении калийного рудника // Безопасность труда в промышленности. - 2019. - № 12. - С. 60-65. DOI: 10.24000/0409-2961-12-60-65.

5. Воронин В.Н. Основы рудничной аэро-газодинамики. - М.; Л.: Углетехиздат, 1951. - 492 с.: ил.

6. Левин Л.Ю., Исаевич А.Г., Семин М.А., Газизуллин Р.Р. Исследование динамики пылевоздушной смеси при проветривании тупиковой выработки в процессе работы комбайновых комплексов // Горн. журн. - 2015. - № 1. - C. 72-75. DOI: 10.17580/gzh.2015.01.13.

7. Tariq F., Bekir G. Evaluation of line brattice length in an empty heading to improve air flow rate at the face using CFD // International Journal of Mining Science and Technology. - 2017. - V. 27, № 2. - P. 253-259. DOI: 10.1016/j.ijmst.2017.01.012

8. Torno S., Torano J., Ulecia M., Allende C. Conventional and numerical models of blasting gas behaviour in auxiliary ventilation of mining headings // Tunnelling and Underground Space Technology. - 2013. - V. 34. - P. 73-81. DOI: 10.1016/j.tust.2012.11.003

9. Xu G., Luxbacher K.D., Ragab S., Xu J., Ding X. Computational fluid dynamics applied to mining engineering: a review // International Journal of Mining, Reclamation and Environment. - 2016. - V. 31. - № 4. - P. 1-25. DOI: 10.1080/17480930.2016.1138570.

10. Флетчер К. Основные положения и общие методы. Т. 1: Пер. с англ. - М.: Мир, 1991. - 502 с.: ил. (Вычислительные методы в динамике жидкостей: В 2 т.)

11. Bardina, J.E., Huang, P.G., Coakley, T.J. Turbulence Modeling Validation, Testing, and Development. NASA Technical Memorandum, 1997. - 110446.

12. Jones, W.P., Launder, B.E. The Prediction of Laminarization with a Two-Equation Model of Turbulence // International Journal of Heat and Mass Transfer. - 1972. - V. 15. - P. 301-314.

13. Wilcox D.C. Turbulence Modeling for CFD. - Second edition. - Anaheim: DCW Industries, 1998. -174 p.

14. Лойцянский Л.Г. Механика жидкости и газа: учебник. - 7-е изд., испр. - М.: Дрофа, 2003. - 840 с.: ил.

\section{РАСЧЕТ ОПРОКИДЫВАНИЯ ВОЗДУШНОЙ СТРУИ В ВЕРТИКАЛЬНЫХ И НАКЛОННЫХ ГОРНЫХ ВЫРАБОТОК ПРИ ПОЖАРЕ ПО ФАКТОРУ ТЕПЛОВОЙ ДЕПРЕССИИ В АНАЛИТИЧЕСКОМ КОМПЛЕКСЕ «АЭРОСЕТЬ»}

\author{
М.Д. Попов ${ }^{1}$, Д.С. Кормщиков ${ }^{2}$ \\ ${ }^{1}$ ООО «Научно-производственное объединение «АэроСфера» \\ ${ }^{2}$ Горный институт УрО РАН, г. Пермь
}

\begin{abstract}
Аннотация: В данной статье приводится описание алгоритма расчета устойчивости при пожаре с учетом тепловой депрессии, применяемого в качестве расчетного модуля в аналитическом комплексе «Аэросеть». Рассмотрены основные особенности алгоритма и инструменты для графического анализа результатов вычисления естественной тяги, вызванной действием пожара на вентиляционную сеть.

Ключевые слова: шахтная вентиляция, горная выработка, подземный пожар, тепловая депрессия, естественная тяга, устойчивость проветривания, расчет воздухораспределения, вентиляционная сеть.
\end{abstract}

\section{Введение}

Тенденция развития горнодобывающей отрасли в последние десятилетия характеризуется увеличением мощности добычи полезных ископаемых. При этом 